\title{
DA EDUCAÇÃo AMBIENTAL PAULISTA: BREVE ANÁLISE ACERCA DO DECRETO ESTADUAL № 63.456 DE 5 DE JUNHO DE 2018
}

Leticia Rodrigues Biassoti, Beatriz Rezende Pereira Souza, Fábio Ferreira Morong.

Universidade do Oeste Paulista - UNOESTE, Curso de Direito, Presidente Prudente, SP. E-mail: leticiabiassoti@outlook.com;

\section{RESUMO}

O objetivo do presente artigo é verificar a aplicabilidade do decreto no 63.456 de 2018 à luz da Lei no 12.780 de 2007, por meio da comparação das normas mediante um breve estudo quanto a sua vigência em meio à sociedade, para observar a abrangência do mencionado decreto em virtude da lei anteriormente criada, mas até então não regulamentada, que a partir de agora produzirá seus efeitos jurídicos. Aplicou-se o método dedutivo para sistematizar os dados coletados e consultas à legislação nacional, estadual, doutrinas e artigos científicos. Conclui-se que, embora ainda exista uma carência normativa no que tange a própria visualização da aplicação prática dos artigos deste instrumento legal, inegável é a sua importância e evolução no que diz respeito à implementação da educação ambiental de nível estadual.

Palavras-chave: Meio ambiente. Educação. Decreto. Lei. Estadual.

\section{PAULIST ENVIRONMENTAL EDUCATION: BRIEF ANALYSIS OF DECREE 63.482 OF JUNE 5, 2018}

\begin{abstract}
The purpose of this article is to check the applicability of Decree 63.456 of 2018 in light of Law No. 12,780 of 2007 , by means of a comparison of the rules by means of a brief study about their validity in the company, in order to observe the scope of said decree by virtue of the previously established but previously unregulated law, which from now on will produce its legal effects. The deductive method was used to systematize the collected data and consultations to national, state legislation, doctrines and scientific articles. It is concluded that, although there is still a lack of normative regarding the actual visualization of the practical application of the articles of this legal instrument, it is undeniable its importance and evolution regarding the implementation of statelevel environmental education.
\end{abstract}

Keywords: Environment. Education. Decree. Law. State. 


\section{INTRODUÇÃO}

A idealização de uma Educação Ambiental abrange programas educacionais, políticas aplicadas que permitem disseminar as informações sobre o tema, bem como construir conhecimento e conscientização de práticas socioambientais no cotidiano, para que os cidadãos tenham a capacidade de enxergar o outro e o planeta como o espelho de si mesmos, e de seu futuro.

A regulamentação de políticas estaduais para a promoção da educação ambiental faz-se necessária, com o propósito de fomentar a inserção das leis na sociedade de forma fiel e eficaz. Entretanto, o Estado de São Paulo era o único a não possuir regulamentação local quanto a Política de Educação Ambiental, em que foi instituída nos demais Estados em 1999 e reformulada em 2005. Há onze anos, a Rede Paulista de Educação Ambiental batalhava pela aprovação dessa política em âmbito estadual, jamais existente anteriormente. (Rede de Ação Política pela Sustentabilidade, 2018).

Em 05 de junho de 2018, o governador do Estado de São Paulo, Márcio França, sancionou o decreto no 63.456, juntamente com a RAPS atuando na articulação do referido decreto. Tal regulamentação, promove a aplicabilidade social da Política Estadual de Educação Ambiental, instituída pela Lei no 12.780 , de 30 de novembro de 2007. O propósito é a implementação do Programa de Educação Ambiental pelo diálogo com a sociedade, bem como coordenar as ações de preservação ambiental tanto na educação formal, como na não-formal, por meio do Conselho Estadual de Educação Ambiental e da Comissão Interinstitucional de Educação Ambiental.

O objetivo do presente artigo é verificar a aplicabilidade do decreto no 63.456 de 2018 à luz da Lei no 12.780 de 2007, por meio da comparação das normas mediante um breve estudo quanto a sua vigência em meio à sociedade, para observar a abrangência do mencionado decreto em virtude da lei anteriormente criada, mas até então não regulamentada, que a partir de agora produzirá seus efeitos jurídicos.

\section{METODOLOGIA}

O presente trabalho teve como método aplicado o dedutivo, já que "a dedução é o caminho das consequências, pois uma cadeia de raciocínio em conexão descendente, isto é, do geral para o particular, leva à conclusão" (ANDRADE, 2010, p. 119), com o objetivo de realizar uma análise acerca do Decreto no 63.456 de 5 de junho de 2018, seus aspectos negativos e positivos, sua aplicabilidade em favor da sociedade, com a utilização de pesquisa à legislação nacional, doutrinas relevantes e artigos científicos jurídicos.

\section{EDUCAÇÃO AMBIENTAL DA NORMA CONSTITUCIONAL E O MEIO AMBIENTE}

A Educação Ambiental, que também tem amparo na lei 9.795/99, atualmente pode ser entendida como um tema transversal que, de acordo com os Parâmetros Curriculares Nacionais PCNs, é compreendida como um conjunto de conhecimentos que envolvem Meio Ambiente, Ética, Pluralidade Cultural, Saúde e Orientação Sexual (LIMA, MORONG, 2017).

O ordenamento jurídico é composto por um sistema de escalonamento de normas, por meio de um modelo piramidal, devendo a Carta Magna permanecer no topo da ilusória pirâmide. Dessa maneira, a norma constitucional atua como um conjunto de normas positivas que regulamentam normas gerais, o que resulta o ensinamento de que a validade de uma norma infraconstitucional depende da observância de uma condição de constitucionalidade (FILHO, 2015).

Para Novaes et. al. (2017, p.89) o artigo 225 da Constituição Federal define os responsáveis pela guarda e preservação deste direito, constando também o dever de se promover a educação 
ambiental em todos os níveis de ensino, assim como, a conscientização pública para a preservação do meio ambiente (inciso $\mathrm{VI}$ ), elemento indispensável para a tutela do direito ambiental.

Sendo assim, trata-se de norma suprema e constitucionalíssima, que deve ser respeitada, preservada e acima de tudo aplicada, por meio dos preceitos e regramento trazidos pelas normas infraconstitucionais, recurso disponibilizado para tanto.

\section{EDUCAÇÃO AMBIENTAL EM ÂMBITO NACIONAL}

Em 1999, fora promulgada a Lei no 9.795, tal norma objetivou a construção de valores sociais, conhecimentos, habilidades, atitudes e competências, a fim de conservar o meio ambiente, que passou a tratar a Educação Ambiental como direito fundamental do cidadão, assim como deveres constitucionais de cidadania. (BRASIL, 1999).

Portanto, para Silva (2016) esta lei veio estabelecer normas e critérios para a educação ambiental, tanto no ensino formal, que ocorre nas unidades de ensino, de modo a estar presente em todas as áreas do conhecimento, como no não-formal, definição dada no art. 13, da referida lei, que se expressam pelas ações e práticas educativas direcionadas à sensibilizar a coletividade sobre as questões ambientais, igualmente quanto à sua organização, e participação desses indivíduos na defesa da qualidade do meio ambiente.

\section{EDUCAÇÃO AMBIENTAL EM ÂMBITO ESTADUAL}

No Estado Democrático de Direito, a tutela e a defesa dos direitos dos cidadãos são atribuídas ao governo, que deve fornecer meios para que haja o efetivo e real usufruto dos mesmos, deste modo, criam mecanismos tais como as Políticas Públicas. São elas: “(...) a totalidade de ações, metas e planos que os governos (nacionais, estaduais ou municipais) traçam para alcançar o bem-estar da sociedade e o interesse público", os governantes ainda selecionam suas prioridades, de acordo com a maior demanda e expectativa social. (SEBRAE, 2008, p. 5)

A Educação ambiental em âmbito estadual é de fato uma prioridade. No que tange ao Estado de São Paulo, em 2008, fora instituída a Coordenadoria de Educação Ambiental (CEA), com o objetivo de estimular as ações em Educação Ambiental, que segue as diretrizes estabelecidas pelo Sistema Ambiental Paulista e pelas Políticas Nacional e Estadual de Meio Ambiente. Em 2017, a coordenadoria passou por uma renovação, na tentativa de firmar sua identidade e incentivar ainda mais a educação ambiental como forma do exercício da cidadania, com mais participação na elaboração e implementação de políticas públicas. (SÃO PAULO, 2018).

Assim como a CEA, em 30 de novembro de 2007, fora promulgada a Lei no 12.780 que instituiu a Política Estadual de Educação Ambiental e tão somente agora, em 5 de junho de 2018, ganhou regulamentação com o Decreto no 63.456 que instituiu a Comissão Interinstitucional de Educação Ambiental (CIEA).

De acordo com Lehfeld (2014), a Lei Estadual de 2007, traz como objetivos fundamentais:

a) a construção de uma sociedade ecologicamente responsável, economicamente viável, culturalmente diversa, politicamente atuante e socialmente justa; b) o incentivo da participação comunitária ativa, permanente e responsável na proteção, preservação e conservação do equilíbrio do meio ambiente em suas diversas dimensões (natural, cultural, artificial).

Nesse sentido, percebe-se que esta é de fundamental relevância, uma vez que traça objetivos a serem seguidos, princípios como a vinculação entre a ética, a educação, a saúde pública, comunicação, o trabalho e as práticas socioambientais, que indica os caminhos pedagógicos voltados aos principais autores dessa construção - crianças, adolescentes e jovens bem como exige uma maior capacitação dos professores, que desempenham o papel de estimuladores na preservação do meio ambiente como valor social para a dignidade da pessoa humana e o pleno exercício da cidadania. (LEHFELD, 2014). 


\section{DECRETOS}

De acordo com Pietro (2018, p. 282), "Decreto é a forma de que se revestem os atos individuais ou gerais, emanados do Chefe do Poder Executivo", estes como as leis, podem conter regras gerais direcionadas a todas as pessoas ou ainda específicas a uma pessoa ou a um grupo de pessoas. No primeiro contexto, o decreto geral produz efeitos regulamentares ou de execução, ou seja, para a fiel aplicação da lei, revelando-a para a sociedade.

\section{DO DECRETO E SEUS ASPECTOS RELEVANTES}

O Decreto № 63.456/2018 em seu art. 1ำ proporciona a implementação da Política Estadual de Educação ambiental, por meio das secretarias da Educação e do Meio Ambiente, em que são responsáveis pela coordenação da "Educação Formal" e da "Educação Não-Formal" (BRASIL, 2018). Esta acertada medida, possibilita cumprir as determinações dos artigos 14 ao 22 da Lei no 12.780/2007, que atuam em diferentes âmbitos.

A formal desenvolvida na educação básica e superior, que de acordo com o art. 15 da Lei no 12.780/2007 “(...) visa respeitar e valorizar a história, a cultura e o ambiente para criar identidades, fortalecendo a cultura local e reduzindo preconceitos e desigualdades. " (BRASIL, 2007). A não-formal, tem por objetivo a criação de instrumentos que viabilize a comunicação de massa, com campanhas educativas e direcionadas a tecnologias sustentáveis, por meio de recursos midiáticos.

No intuito de fortalecer esses mecanismos, o artigo 2o do Decreto, instituiu a CIEA, composto por governantes e membros da sociedade, que objetiva acompanhar e avaliar a Política Estadual e a execução do Programa Estadual de Educação Ambiental instituído pelo Decreto estadual no 55.835 de 1 을 de fevereiro de 2010. Na garantia de democratização o artigo 8으 do Decreto no 63.456/2018 em seu inciso II, promove a participação popular na discussão, elaboração, execução, monitoramento e avaliação do próprio Programa e ainda fortalece a diversidade por meio de diferentes grupos sociais e regiões do Estado de São Paulo, no inciso III. (BRASIL, 2018).

Ainda em relação à participação, o item $12, \S 4$ o do art. 40 do Decreto de 2018, relaciona-se implicitamente com o art. 8으, da Lei Estadual de 2007, que com a destinação de vagas para representantes de movimentos sociais e organização da sociedade civil, possibilita a aplicação dos princípios básicos da Educação Ambiental, tais como: o enfoque humanístico, sistemático, democrático, a pluralidade de ideias sob o enfoque da sustentabilidade.

O $1^{\circ}$ do art. 4 do Decreto faz menção a estruturação da Comissão Interinstitucional de Educação Ambiental, que autoriza a coordenação da Política Estadual a obter apoio dos órgãos integrantes da Administração Pública direta e indireta. (BRASIL, 2018). Todavia, a Lei de 2007 é mais abrangente, e em seu art. 7으, menciona o setor privado e as devidas preocupações que este deve ter na execução de suas atividades, como processos produtivos, obras e exploração de recursos naturais, não sendo regulamentada de fato a implementação do setor privado na Comissão para o cumprimento do princípio da pluralidade de ideia, citado acima, ou seja, atuar de forma funcional na Educação Ambiental, com novos pontos de vista. (BRASIL, 2007).

Imprescindível fora a regulamentação do Decreto para a devida aplicação da Lei, no entanto, nota-se uma incongruência na medida em que se compara a quantidade literal dos artigos, enquanto o primeiro possui 36, o segundo, comporta apenas 10, o que torna sua aplicação defasada socialmente, pois, se concentra em tratar de formas de organização internas, administrativas, sem proposta clara na prática.

\section{CONCLUSÃO}

O tema Educação Ambiental tem sido pauta de estudos acadêmicos e a integração dessa preocupação desde a mais tenra idade é louvável. Assim, a sociedade vem conscientizando-se e 
com isso, os governos devem estar mais atentos às políticas públicas direcionadas à concretização dessas ações voltadas à educação ambiental, de maneira a direcionar os cidadãos a uma educação reflexiva e crítica.

Constata-se que o Decreto criou o vínculo que precisava ter sido concebido há 9 anos junto à Lei $n^{\circ} 12.780$ de 2007, uma vez que atualmente existe a devida regulamentação, bem como uma Comissão que coordena e fiscaliza o funcionamento das propostas pertinentes. Destarte, embora ainda exista uma carência normativa no que tange a própria visualização da aplicação prática dos artigos, inegável é a sua importância e evolução no que diz respeito à implementação da educação ambiental de nível estadual.

\section{REFERÊNCIAS}

ANDRADE, Maria Margarida de. Introdução à metodologia do trabalho científico: elaboração de trabalhos na graduação.10. ed. São Paulo: Atlas, 2010. Disponível em: <https://integrada.minhabiblioteca.com.br/books/9788522478392/pageid/135> Acesso em 13. ago. 2018.

BRASIL. LEI № 12.780, DE 30 DE NOVEMBRO DE 2007. Institui a Política Estadual de Educação Ambiental. São Paulo, nov. 2017. Disponível em: <https://www.al.sp.gov.br/repositorio/legislacao/lei/2007/lei-12780-30.11.2007.html> Acesso em: 15. ago. 2018

BRASIL. DECRETO № 63.456, DE 05 DE JUNHO DE 2018. Regulamenta a Política Estadual de Educação Ambiental, instituída pela Lei no 12.780, de 30 de novembro de 2007, institui a Comissão Interinstitucional de Educação Ambiental e dá providências. São Paulo, jun. 2018 Disponível em: <https://www.al.sp.gov.br/repositorio/legislacao/decreto/2018/decreto-63456-05.06.2018.html> Acesso em: 15. ago. 2018

BRASIL. LEI № 9.795, DE 27 DE ABRIL DE 1999. Dispõe sobre a educação ambiental, institui a Política Nacional de Educação Ambiental e dá outras providências. Brasília, DF, abr. 1999. Disponível em: < http://www.mma.gov.br/port/conama/legiabre.cfm?codlegi=321> Acesso em: 13. ago. 2018.

BRASIL. Constituição. (1988). Constituição da República Federativa do Brasil. Brasília: Senado Federal, 2016.

FILHO, Manoel Gonçalves Ferreira. Princípios fundamentais do direito constitucional: o estado da questão no início do século XXI, em face do direito comparado e, particularmente, do direito positivo brasileiro. 4. ed. São Paulo: Saraiva, 2015. Disponível em: <https://integrada.minhabiblioteca.com.br/\#/books/9788502220782/cfi/0.> Acesso em 13. ago. 2018.

LEHFELD, Lucas de Souza. Ensaio sobre educação ambiental. 2014. Disponível em: <http://genjuridico.com.br/2014/10/22/ensaio-sobre-educacao-ambiental/> Acesso em: 16. ago. 2018

LIMA, Natália Lorençoni, MORONG, Fábio Ferreira. A relação do autismo com o meio ambiente e a educação ambiental: breves comentários. Colloquium Socialis, Presidente Prudente, v. 01, n. Especial 2, Jul/Dez, 2017, p.120-126. DOI: 10.5747/cs.2017.v01.nesp2.s0124. https://doi.org/10.5747/cs.2017.v01.nesp2.s0124 
NOVAES, Rogério Alves. et. al. A influência da Educação Ambiental na preservação do meio ambiente. Disponível

em: <htttp://www.unoeste.br/site/enepe/2017/suplementos/area/Socialis/01\%20\%20Direito/A\%20INFLU\%C3\%8ANCIA\%20DA\%20EDUCA\%C3\%87\%C3\%830\%20AMBIENTAL\%20NA \%20PRESERVA\%C3\%87\%C3\%830\%20DO\%20MEIO\%20AMBIENTE.pdf> Acesso em: 16. ago. 2018.

PIETRO, Maria Sylvia Zanella Di. Direito administrativo. 31. ed. rev. atual e ampl. Rio de Janeiro: Forense, 2018. Disponível em: <https://integrada.minhabiblioteca.com.br/\#/books/9788530979577/cfi/6/2!/4/2@0:0> Acesso em: 14. ago. 2018

REDE DE AÇÃO POLíTICA PELA SUSTENTABILIDADE. Com auxílio da RAPS, Política Estadual de Educação Ambiental é sancionada em São Paulo. 2018. Disponível em: <https://www.raps.org.br/governo-de-sao-paulo-sanciona-decreto-criando-a-politica-estadual-deeducacao-ambiental/ > Acesso em 16. ago. 2018.

SÃO PAULO, 2018. Coordenadoria de Educação Ambiental. Disponível em: <http://www2.ambiente.sp.gov.br/cea/> Acesso em 14. ago. 2018

SEBRAE, MG. Políticas públicas: conceitos e práticas. Caldas - Belo Horizonte : Sebrae/MG, 2008. Disponível em: < http://bis.sebrae.com.br/bis/conteudoPublicacao.zhtml?id=2859> Acesso em: 14. ago. 2018

SILVA, Ronaldo Gomes da. Política Nacional da Educação Ambiental: formal e não-formal. Disponível em: <https://jus.com.br/artigos/48484/politica-nacional-da-educacao-ambientalformal-e-nao-formal> Acesso em: 13. ago. 2018 